Reprod. Nutr. Dévelop., 1982, 22 (3), 569-574.

\title{
Tetraploidy induced by heat shocks in the rainbow trout (Salmo gairdneri R.).
}

D. CHOURROUT

Laboratoire de Physiologie des Poissons, I.N.R.A. 78350 Jouy-en-Josas, France

Summary. In this study, 1 attempted to induce tetraploidy in the rainbow trout by means of $28^{\circ} \mathrm{C}$-heat shocks applied to fertilized eggs. Variations in the parameters of treatment resulted in large differences in survival rates between the batches, and varying proportions of tetraploid, diplotetraploid and diploid embryos were obtained with shocks beginning between $6 \mathrm{~h} 30 \mathrm{~min}$ and $9 \mathrm{~h}$ after fertilization and lasting more than $14 \mathrm{~min}$. Tetraploidy was always associated with high mortality rates.

\section{Introduction.}

Depending on the particular ploidy of the fertilized eggs treated, the technique inducing chromosome doubling can be used to attain three objectives : 1) the direct production of homozygous diploid fish from haploid eggs, 2) the production of tetraploid fish from diploid control eggs, and 3) the production of allotetraploid fish from diploid hybrid eggs. Such original genotypes may be useful in solving two major problems in aquaculture, i.e. the control of reproduction (sterile triploid fish obtained by crossing diploid and tetraploid parents) and genetic improvement by seeking heterosis after crossing distinct inbred lines or by using allotetraploidy as a way of obtaining " new species $"$.

The induction of tetraploidy, first described in plants (Blakeslee and Avery, 1937) and later in amphibians (Fischberg, 1958; Romanovski and Spicarova, 1961 ; Jaylet, 1972 ; Reinschmidt et al., 1979) and mammals (Snow, 1973), involves the use of conventional antimitotic chemicals like colchicine in plants and cytochalasin B in mammals. A preliminary study with cytochalasin B only produced polyploid mosaics in salmonid fish (Refstie et al., 1977), and the karyotype of some adults recovered from the corresponding treated eggs was interpreted as resulting from the doubling of only a part of the chromosome complement (Refstie, 1981). Except for one recent study using hydrostatic pressure in Xenopus laevis (Reinschmidt et al., 1979), the most common way to produce tetraploid embryos in amphibians is the use of heat shocks applied to eggs beginning their first cleavage ; this sensitive stage corresponds to a late interphase of second mitosis and, as demonstrated by Gaillard and Jaylet (1975), 
the heat treatment induces an aberration in the spindle formation after the aster movements have been inhibited. The experimenter just has to heat-shock the cleaving eggs (selected with the naked eye) and 100 p. 100 tetraploidy can be obtained (Jaylet, 1972) with a relatively high survival rate (30 p. 100). Attempts with the same heat shocks at the time of metaphase-anaphase of the first mitosis do not give any results (Jaylet and Ferrier, personal communication) no do similar heat shocks applied at cleavage after gynogenetic activation, except when the eggs are taken from highly inbred females (Reinschmidt et al., 1979). Recently, when the homozygous diploid fish were produced in Brachydanio rerio with hydrostatic pressure shocks (Streisinger et al., 1981), the mothers used were selected on the basis of the " good " haploid morphology they had shown in previous experiments.

Heterozygous gynogenetic diploids, recently induced in the rainbow trout by $10-$ min heat treatments of 24 to $29{ }^{\circ} \mathrm{C}$ (Chourrout, 1980), were demonstrated to be viable; in these experiments, I used the hatching rate to estimate the retention rate of the second polar body. When I tried to induce homozygous diploidy with similar treatments (unpublished), I obtained low hatching rates that were not significantly different from that of spontaneous diploidy occuring in the controls, perhaps because of excessive inbreeding. Therefore, I attempted to induce chromosome doubling from diploid eggs, expecting to produce tetraploid embryos, and to use karological methods to estimate the success rate. The main difficulty with my model (rainbow trout) was that cleavage could not be observed in vivo and there was no precise morphological or histological chronology of early developmental events. I thus had to treat complete batches without selecting the cleaving eggs.

Preliminary experiments, using heat shocks (duration : 2 to $20 \mathrm{~min}$ at temperatures between 26 and $32{ }^{\circ} \mathrm{C}$ ) applied between $4 \mathrm{~h} 20 \mathrm{~min}$ and $5 \mathrm{~h} 30 \mathrm{~min}$ after fertilization, did not produced any tetraploids but a recent paper (Thorgaard et al., 1981) testing heat shocks of 1-min duration, all applied $5 \mathrm{~h}$ after fertilization and at higher temperatures $\left(34-37^{\circ} \mathrm{C}\right)$, reported low rates of tetraploidy.

\section{Material and methods.}

In the 3 experiments performed, rainbow trout sperm was removed by abdominal pressure. In experiment 1, the batches of eggs taken from 12 threeyear old females contained about 800 eggs each ; in experiment 2 using 3 twoyear old females, the batches contained about 3000 eggs each ; in experiment 3 , we used 11 two-year old females and the batches contained about 1500 eggs each. All the females were at their first sexual maturation.

Artificial fertilization involved mixing $1 \mathrm{ml}$ of sperm and 1000 eggs followed by immediate dilution with an appropriate saline-buffered solution (Billard, 1974). Ten $\min$ later, the eggs were transferred to a thermoregulated $\left(10{ }^{\circ} \mathrm{C}\right)$ recirculating system ; this moment was defined as development time zero. 
The heat shocks were characterized by 3 parameters : 1) temperature $28{ }^{\circ} \mathrm{C}$, 2) duration of treatment (T) : 8 to $23 \mathrm{~min}$, and 3) age (t) at which the shock began : between $5 \mathrm{~h} 30 \mathrm{~min}$ and $10 \mathrm{~h} 30 \mathrm{~min}$. I localized the beginning of the first cleavage on fixed eggs as between 7 and $8 \mathrm{~h}$, although the stages of furrow progression were not as definite as in amphibians. The survival rates were scored on Day 17 (tail-bud stage) and Day 40 after hatching.

The tail epithelium of the embryos (Day 17) and the gill epithelium of the hatched fry (Day 50) were karyologically examined after 6 to $15 \mathrm{~h}$ in $0.2 \mathrm{p} .1000$ colchicine. Day-17 embryos were removed from the eggs in $0.7 \mathrm{p} .100 \mathrm{NaCl}$ and kept in tap water for 20 min for hypotonic treatment. The gills of Day-50 fry were dissected and kept in tap water for $\mathbf{4 5} \mathrm{min}$.

In both cases, the organs were fixed in ethanol-acetic acid (3:1) for $3 \mathrm{~min}$, rinsed in distilled water and then gently dissociated in a drop of 50 p. 100 acetic acid on the slide; the drop was squashed under a coverslip that was removed with 50 p. 100 acetic acid. The slide was then rinsed and stained in 4 p. 100 Giemsa for $10 \mathrm{~min}$.

\section{Results.}

Survival rate (fig. 1). - Large variations in survival rate were observed for a given treatment duration, depending on the age $(t)$ of the eggs. According to experiment 1 and experiment 3 , clear ranges of $t$ seemed to correspond either to the low sensitivity of the eggs to heat shocks $(6 \mathrm{~h} 30 \mathrm{~min}$ to $7 \mathrm{~h}$ in exp. $1 ; 8 \mathrm{~h}$ to $8 \mathrm{~h} 30$ in exp. 3) or to a very high mortality (5 h $30 \mathrm{~min}$ to $6 \mathrm{~h}$ in exp. 1 ; $9 \mathrm{~h} 30 \mathrm{~min}$ to $10 \mathrm{~h}$ in exp. 3). Mortality between Day 17 and hatching was often high.

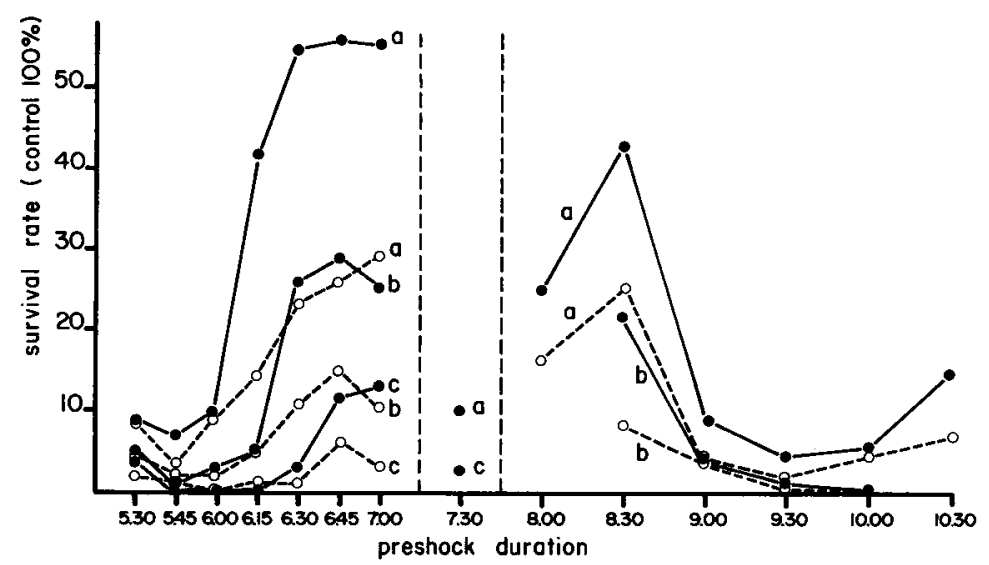

FIG. 1. - Survival rates in treated batches of embryos at Day 17 (solid lines) and of hatched fry at Day 50 (dotted lines). Preshock duration varied from $5 \mathrm{~h} 30 \mathrm{~min}$ to $7 \mathrm{~h}$ in exp. 1, from $8 \mathrm{~h}$ to $10 \mathrm{~h} 30 \mathrm{~min}$ in exp. 3 and was $7 \mathrm{~h} 30$ in exp. 2. Series a, b, c correspond to 14, 17 and 20-min shock duration, respectively. 
Karyological examination (figs. 2, 3).

Experiment 1. - Tail-bud stage karyology was limited to batches with relatively low mortality; this explains the lack of data on long-duration batches. The karyology of hatched fry on Day 50 revealed tetraploids only in batches treated for at least $14 \mathrm{~min}$; a majority of those batches contained varying proportions of diploid, diplotetraploid mosaics and tetraploid fry. The rates of abnormal fry were not recorded in experiment 1.

Experiment 2. - This experiment revealed an interesting rate of tetraploid embryos with high associated mortality before and after Day 17 (batch $\mathrm{t}=7 \mathrm{~h} 30 \mathrm{~min} ; \mathrm{T}=20 \mathrm{~min}$ ) ; ( could not confirm the post-hatching survival of these embryos due to lack of karyological data on Day 50.

Experiment 3. - Karyological examination and survival rates at the tail-bud stage led me to select one batch ( $\mathrm{t}=8 \mathrm{~h} 30 \mathrm{~min} ; \mathrm{T}=14 \mathrm{~min}$ ) for further study; about two-thirds of the $\mathbf{1 8 0}$ hatched fry in that batch were normal and one-third were abnormal. Karyological study on Day 50 did not reveal any tetraploids in the normal individuals, although a few diplotetraploids were identified. However, a large proportion of mosaics and tetraploids were found in a sample of the abnormal fry.

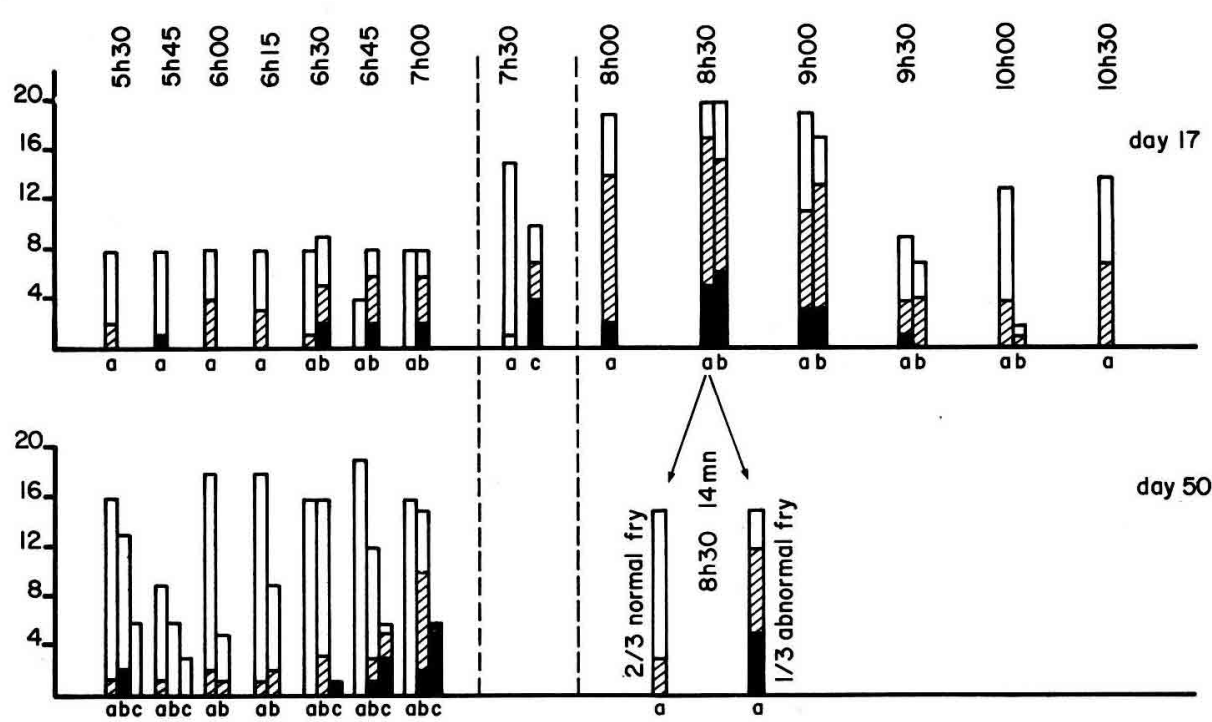

FIG. 2. - Karyology at Days 17 and 50. Y-axis : the number of embryos or fry analyzed in each batch characterized by preshosk and shock duration $(a, b, c)$. Each vertical bar represents the karyological results of one batch. The numbers of diploid, diplotetraploid and tetraploid individuals of a given batch are illustrated by the length of the white, hatched and black rectangles, respectively; for instance, 15 fry were analysed at Day 50 in the $7 \mathrm{~h}-17$ min batch; out of these, 5 were diploid, 8 were diplotetraploid and 2 were tetraploid. 


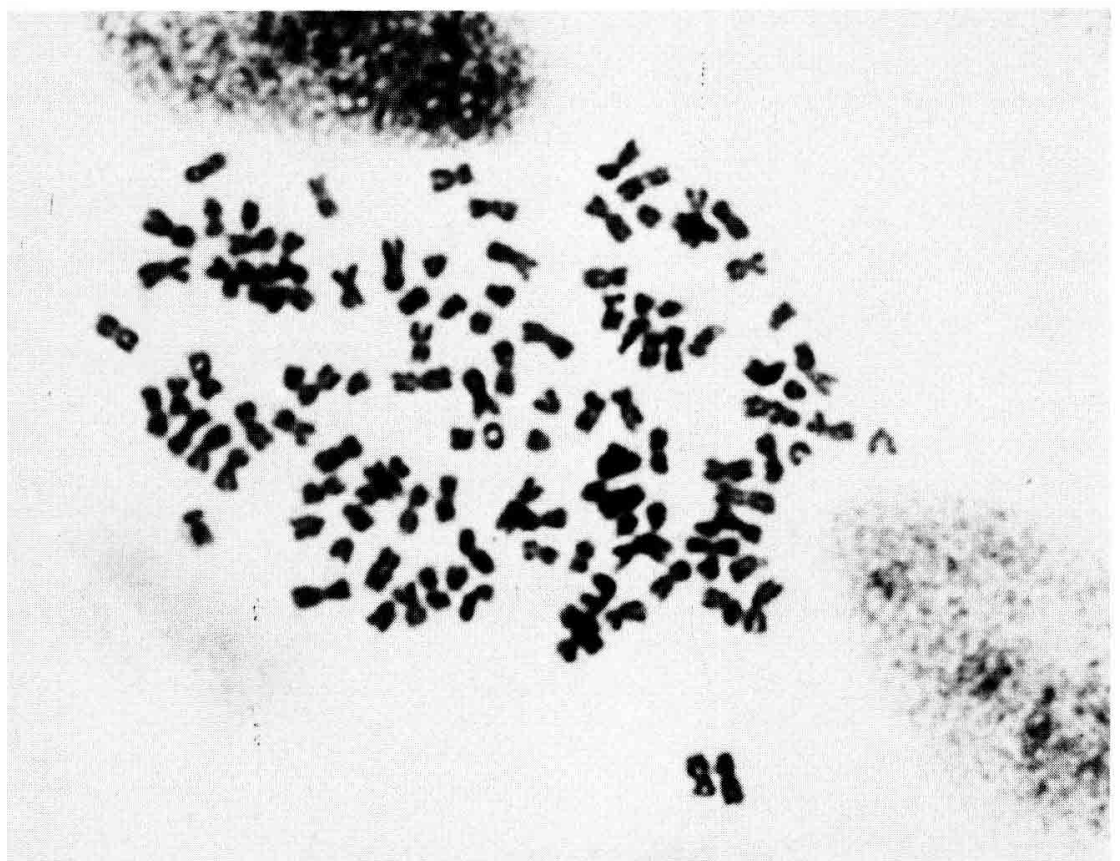

FIG. 3. - Tetraploid metaphase.

\section{Discussion.}

The embryonic survival rates in the batches containing tetraploids were always very low, not being higher than those recorded by Thorgaard et al. (1981). However, since the frequency of tetraploidy within the survivors was higher in our study, some of the treatments proposed here might be useful if applied to a large number of eggs.

Although I did not obtain any success with treatments applied before $5 \mathrm{~h} 30$ of development, the results do not disagree with those of Thorgaard et al. (1981); those authors tested heat shocks of different durations and temperatures, and the low percentages of tetraploids they obtained (16 p. 100 for the best treatment) showed that tetraploids might not be detected in the samples of the 15 embryos I had analyzed in the premilimary experiments. I therefore decided to test treatments applied at later stages, expecting to induce the mechanism described by Gaillard and Jaylet (1975) in newts ; in that case, the obtention of various proportions of diplotetraploid embryos confirms the action on eggs having probably two, or possibly more, nuclei.

A « troubling " result was found in the $(t=8 \mathrm{~h} 30 ; \mathrm{T}=14 \mathrm{~min}$ ) batch (experiment 3): all the tetraploid fry were abnormal in appearance. Although Thorgaard (personal communication) also has doubts about the viability of tetraploids, it seems too early to draw any conclusions on this subject.

Finally, as compared to results in amphibians, the yield of tetraploidy is low. 
Asynchrony of the developing eggs might be one of the reasons. Fischberg (1958), working on newts, observed this asynchrony within and between spawns; the fact that sensitive, cleaving amphibian eggs can be selected with the naked eye is important in obtaining high rates of tetraploidy. Two kinds of indirect experiments could test the validity of such an argument in the future : 1) applying heat shocks in amphibians without selecting the eggs, 2) applying heat shocks in other fish species after selecting the eggs with visible cleavage.

Reçu en octobre 1981

Accepté en janvier 1982

Résumé. Au cours de cette étude, nous avons tenté d'induire la tétraploïdie chez la truite Arc-en-ciel, en appliquant des chocs thermiques à $28{ }^{\circ} \mathrm{C}$ aux œufs fécondés. Les variations des paramètres du traitement se sont traduites par de grandes différences de survie entre les lots correspondants; des proportions variées d'embryons tétraploïdes, diplotétraploïdes et diploïdes ont été obtenues lorsque les chocs commençaient entre $6 \mathrm{~h} 30$ et $9 \mathrm{~h}$ après la fécondation et duraient plus de $14 \mathrm{~min}$. L'obtention de tétraploïdes était toujours associée à de forts taux de mortalité.

\section{Références}

BILLARD R., 1974. L'insémination artificielle de la Truite Salmo gairdneri Richardson. IV. Effet des ions $\mathrm{K}$ et $\mathrm{Na}$ sur la conservation de la fertilité des gamètes. Bull. fr. Pisc., 256, 88-100.

BLAKESLEE A. F., AVERY A. G., 1937. Methods of inducing chromosome doubling in plants by treatment with colchicine. Science, 86, 408.

CHOURROUT D., 1980. Thermal induction of diploid gynogenesis and triploidy in the eggs of the rainbow trout (Salmo gairdneri Richardson). Repr. Nutr. Dévelop., 20, 727-733.

FISCHBERG M., 1958. ' Experimental tetraploidy in newts. J. Embryol. exp. Morph., 6, 393-402.

GAILLARD G., JAYLET A., 1975. Mécanisme cytologique de la tétraplö̈die expérimentale chez le Triton Pleurodeles walt/ii. Chromosoma (Berl.), 51, 125-133.

JAYLET A., 1972. Tétraploïdie expérimentale chez le Triton Pleurodeles waltiii Michach. Chromosoma (Berl.), 38, 173-184.

REFSTIE T., 1981. Tetraploid rainbow trout produced by cytochalasin B. Aquaculture, 25, 51-58.

REFSTIE T., VASSVIK V., GJEDREM T., 1977. Induction of polyploidy in salmonids by cytochalasin B. Aquaculture, 10, 65-74.

REINSCHMIDT D. C., SIMON S. J., VOLPE E. P., TOMPKINS R., 1979. Production of tetraploid and homozygous diploid amphibians by suppression of first cleavage. J. exp. Zool., 210, 137-143.

ROMANOVSKI A., SPICAROVA N., 1961. The production of tetraploid newts by Fischberg's method. Fol. Biol. (Praha), 7, 395-399.

SNOW M. H. KL., 1973. Tetraploid mouse embryos produced by cytochalasin B during cleavage. Nature, 244, 513-515.

STREISINGER G., WALKER C., DOWER N., KNAUBER D., SINGER F., 1981. Production of clones of homozygous diploid zebra fish (Brachydanio rerio). Nature, 291, 293-296.

THORGAARD G. H., JAZWIN M. E., STIER A. R., 1981. Polyploidy induced by heat shock in rainbow trout. Trans, amer. Fish. Soc., 110, 546-550. 